\title{
Stage IIIC Primary Peritoneal Cancer AJCC v8
}

National Cancer Institute

\section{Source}

National Cancer Institute. Stage IIIC Primary Peritoneal Cancer A/CC v8. NCI Thesaurus. Code C140011.

Stage IIIC includes: T3c, N0/N1, M0. T3c: Primary peritoneal cancer with macroscopic peritoneal metastasis beyond the pelvis more than $2 \mathrm{~cm}$ in greatest dimension with or without metastasis to the retroperitoneal lymph nodes (includes extension of tumor to capsule of liver and spleen without parenchymal involvement of either organ). N0: No regional lymph node metastasis. N1: Positive retroperitoneal lymph nodes only (histologically confirmed). M0: No distant metastasis. (AJCC 8th Ed.) 